\title{
The Effect of Explicit Instruction of Metacognitive Reading Strategies on ESP Reading Compre- hension in Academic Settings
}

\author{
Parviz Ajideh $^{1}$, Mohammad Zohrabi², Kazem Pouralvar ${ }^{3 *}$ \\ ${ }^{1}$ Professor in TEFL, Faculty of Foreign Languages and Persian Literature, English Department, University of Tabriz, Tabriz, Iran \\ ${ }^{2}$ Assistant Professor in TEFL, Faculty of Foreign Languages and Persian Literature, English Department, University of Tabriz, Tabriz, Iran \\ ${ }^{3}$ PhD Candidate in TEFL, Faculty of Foreign Languages and Persian Literature, English Department, University of Tabriz, Tabriz, Iran
}

Corresponding Author: Kazem Pouralvar, E-mail: k.pouralvar@gmail.com

\section{ARTICLE INFO}

Article history

Received: January 04, 2018

Accepted: March 14, 2018

Published: July 01, 2018

Volume: 7 Issue: 4

Advance access: May 2018

Conflicts of interest: None

Funding: None

\begin{abstract}
This study investigated the effect of explicit instruction of metacognitive reading strategies on ESP reading comprehension among university students in Iran. Strategy instruction has recently been integrated into language teaching methodologies, stressing that successful language learners take advantage of appropriate strategy selection and application in order to develop better language skills. Poor learners, on the other hand, fail to know how to use strategies and for what purposes. There has been ample research on the impact of explicit strategy instruction on the EFL learners' language skills. These studies indicate the effectiveness of strategy instruction on the various aspects of language learning such as skill development among EFL learners but the notion of the effectiveness of strategy instruction on ESP reading comprehension in university level has not been much scrutinized in Iranian context. The participants in this study included undergraduate first and second year students studying Islamic Art and Architecture Engineering at Tabriz Islamic Art University. A randomized subjects and posttest-only control group design was employed in this study. The number of students in Art control and experimental groups was 28 and the one for Architecture control and experimental group was 26 students. The participants in the experimental groups received explicit instruction of metacognitive reading strategies through the Cognitive Academic Language Learning Approach (CALLA) for strategy instruction. The results of independent t-test revealed that the students in the experimental groups outperformed those in the control groups and showed greater achievement in their ESP reading comprehension ability.
\end{abstract}

Key words: Reading strategies, Explicit metacognitive strategy instruction, ESP reading comprehension, CALLA

\section{INTRODUCTION}

Perspective second/foreign language learners are those who consciously use appropriate strategies for learning and communicating in a second language. Learners use strategies with the purpose of improving performance in the learning and second language use. Strategies are "conscious actions that learners take to improve their language learning" (Anderson, 2005, p. 757). Strategies can be observable such as taking notes from an academic lecture in order to recall the information better or they can be mental such as thinking about a topic before reading a text. Since strategies are conscious, the learner is actively involved in the process of selection and use. Successful learners take advantage of good strategy selection and use and less successful learners fail to know which strategy to use for what purposes. Less successful learners usually go the same way, that is, they use the same strategy again and again and do not make signif- icant advance in their tasks. They fail to recognize that the strategies they are applying are not helpful and are unaware of other strategies that may help them make better progress and accomplish their goals. Successful learners, on the other hand, capitalize on a handful of useful and appropriate strategies when accomplishing tasks (Naiman, Frohlich $\&$ Todesco, 1975).A single strategy use can also lead to dissatisfaction in learning so, rather than being isolated actions, strategies are used together in learning to achieve desirable results. There is no good or bad strategy in learning. In fact all strategies are useful but the point is about the bad or good application of strategies.

Strategies have also been considered in the context of language teaching methodologies. Often a methodology assumes that if the teacher follows certain steps in teaching, learners will learn what is being taught. This idea underestimates individual differences in learning and the fact that each individual approaches the learning based on their own 
learning style and strategy make-up. Oxford (1993) points out that no single method can meet the needs of all learners and Nunan (1991) further states that individual learners apply a variety of strategies and take up learning a language differently, a fact that is not considered carefully within the context of most of the methods of language teaching.

One of the issues that has recently been integrated into language teaching methodologies is the notion of strategy instruction. The rationale behind this is that learners can achieve higher levels of language achievement when they are explicitly taught language learning strategies and when they are given the opportunity to realize not only what they can learn in the language classroom, but also how they can learn the language they are studying (Graham \& Harris, 2000).

Strategy instruction has also received interest within the context of language skills. There has been ample empirical research on the influence of strategy-based instruction on the learners' improved abilities in language skills. Reading skill has specifically received wide attention, especially in academic settings, due to the great role this skill plays in university students' academic achievements (Anderson, 2002). In Iran, language teaching in universities is limited to some general courses and, in most of the areas, an ESP course in the students' technical fields in which the emphasis is put on the students' improvement of reading comprehension. The conventional method usually applied in approaching reading comprehension skill is generally translation of technical texts from English into Persian so that the students understand the content and the meaning expressed throughout the texts. Students spend painstaking hours of translating texts both inside and out of the classrooms by using bilingual dictionaries and other resources but they do not attain the desired outcomes that indicate their improved abilities in the reading skill. In other words, the reading skill is considered as a passive activity in which strategy use and instruction plays the least important role (Tavakoli\&Koosha, 2016).

\section{Objectives of the Study}

Until recently, there has been very little empirical research into exploring the possible effect of explicit strategy instruction on learners' ESP reading in academic settings within Iranian context. As part of a PhD dissertation, the present study aims at investigating the effect of explicit instruction of metacognitive reading strategies on Art and Engineering students' ESP reading comprehension in university level in Iranian context. To this end, the following research questions and hypotheses are considered in this study:

1- Is there any effect of explicit instruction of metacognitive reading strategies on Art Students' ESP reading comprehension ability?

H0: There is no effect of explicit instruction of metacognitive reading strategies on Art Students' ESP reading comprehension ability.

$\mathrm{AH}$ : There is any effect of explicit instruction of metacognitive reading strategies on Art Students' ESP reading comprehension ability.
2- Is there any effect of explicit instruction of metacognitive reading strategies on Engineering Students' ESP reading comprehension ability?

$\mathrm{H} 0$ : There is no effect of explicit instruction of metacognitive reading strategies on Engineering Students' ESP reading comprehension ability.

$\mathrm{AH}$ : There is any effect of explicit instruction of metacognitive reading strategies on Engineering Students' ESP reading comprehension ability.

\section{REVIEW OF THE RELATED LITERATURE}

\section{Classification of Language Learning Strategies}

Language learning strategies have been generally classified into seven major categories: cognitive strategies (e.g., identifying, retention, and storage of learning materials as well as retrieval, rehearsal, and comprehension), metacognitive strategies (e.g., preparing and planning, identifying, monitoring, orchestrating, and evaluating strategy use), mnemonic or memory-related strategies (e.g., memorization strategies), compensatory strategies (e.g., circumlocution strategies such as using a word you know to describe the meaning of a word or phrase you do not know), affective strategies (e.g. strategies for reducing anxiety), social strategies (e.g., strategies for interacting with others), and self-motivating strategies (e.g., self-encouragement, relaxation, and meditation, eliminating negative influences, creating positive influences). Some of the strategies categorized in this classification overlap such as the strategies in affective and self-motivating categories. Oxford $(1990,2001)$ refers to the first six categories of these strategies but other researchers (Chamot \& O’Malley, 1994; Chamot et al., 1999; Cohen, 1996a; Cohen \& Weaver, 1998) use even fewer number of classification of language learning strategies.

In a recent empirical research to classify language learning strategies, Hsiao and Oxford (2002) had a comparison of the classification theories of language learning strategies by giving Strategy Inventory for Language Learning (SILL) to 517 college foreign language learners in Taiwan. They developed fifteen strategy classifications and tested them based on classification systems proposed by Oxford (1990), Rubin (1981), and O'Maleey and Chamot (1990). The findings of their study supported the six distinctive categories of L2 learning strategies. These categories are classified as cognitive, metacognitive, memory, compensatory, affective and social strategies.

There are a number of tools for identifying, classifying and measuring L2 strategies, the most frequently cited and used ones include standardized inventories, think-aloud protocols, and reflective journals.

Standardized inventories. The most wildly used inventory for identifying L2 strategies is Oxford's (1990) Strategy Inventory for Language Learning (SILL). Oxford and Burry-Stock (1995) reported on the successful use of this inventory in gathering data on language learning strategies. One great advantage of SILL is that reliability and validity data are available. Reported reliabilities for ESL/EFL SILL range from. 86 to. 91 when learners respond to the questionnaires in their second language (English). Translated versions of 
the SILL have been used in many research projects and reliability coefficients ranging from. 91 to. 94 have also been reported.

Another inventory that shows great promise is a more recent instrument developed by Mokhtati and reported in Mokhtari and Sheorey (2002) and Sheorey and Mokhtari (2001). The Survey of Reading Strategies (SORS) focuses on different strategy use within the context of reading. The SORS was built upon a separate metacognitive reading strategy developed for native speakers of English, the Metacognitive-Awareness of Reading Strategies Inventory (MARSI). The SORS inventory measures three kinds of reading strategies: cognitive strategies, metacognitive strategies and support strategies.

Think-aloud protocol. Think-aloud protocols or verbal report data have been applied in many L2 strategy researches to identify strategies used by language learners (Anderson, 1991; Anderson \& Vandergrift, 1996; Cohen \& Olshtain, 1993; Gass \& Mackey, 2001). One of the greatest strengths of think-aloud protocols is that researchers are able to gather data on the process of strategy use. By using this tool, the sequence of strategies that language users implement to complete language tasks is captured.

Three categories of verbal reports have been introduced by Cohen and Scott (1996): self-report, self-observation and self-revelation. Self-report is a statement of typical behavior. Responses to questionnaires are a form of self-report. Self-observation is used simultaneously to complete a language task or within a very short time after completing the task. Self-revelation data refer to analyzed thoughts. One key to the successful use of think-aloud protocols is to gather data as close to the event as possible so that the strategies identified will be those actually used.

Reflective journals. Reflective journals or diaries have been used for several years as a tool for student reflection (Oxford, et al., 1996). In a study conducted by Riley and Harsch (1999) among Japanese English learners the primary tool for gathering data on the learners' strategy use was reflective journal. The journal was intended to be used as a tool to explore learner awareness, learner development, and the use of language learning strategies as well as how guided reflection influences the development of language learning strategies.

\section{Explicit Instruction of Language Learning Strategies}

The integration of explicit instruction of language learning strategies into the classroom curriculum has been given great attention by researchers. For instance, Nunan (1996, p.14) recommends that " language classrooms should have a dual focus, not only on teaching language content but also on developing learning processes as well". The primary aim of instruction is to raise learners' awareness about the existing strategies and then allow each individual to select appropriate strategies to achieve their learning goals.

It is also argued that the most effective strategy instruction takes place when it is integrated into regular classroom instruction (Cohen, 1998; Oxford \& Leaver, 1996). Brown (2002) provides a very practical guide on how to tackle the teaching of language learning strategies in the classroom.
According to him, teachers and learners are instructed through the language learning strategy process in an organized and effective form.

There have been criticisms to strategy instruction and its usefulness in language classes. Rees-Miller (1993, 1994) questions the concept of strategy instruction and states that since the mixed results have been reported from different research studies, teachers should be cautious in accepting the concept of learner-strategy training. She focuses on factors that teachers must take into account when they deal with strategy instruction in their classes. These factors include learners' cultural backgrounds, their age, educational background, life experiences, affective factors, and also the beliefs that learners as well as teachers have about language learning. Chamot and Rubin (1994), in answering questions she raises about strategy instruction, point out that all of these factors influence individual strategy use. The fact is that no single strategy is used in isolation, but rather in an orchestrated manner with other strategies as part of a process. This should not suggest that strategy instruction is not effective, but rather give teachers increased insight into the various factors they take into consideration when strategy instruction is undertaken.

\section{Models of Strategy Instruction}

There have been two main approaches about strategy instruction in the context of language methodologies: Styles and Strategies-Based Instruction (SSBI) and the Cognitive Academic Language Leaning Approach (CALLA). SSBI is an approach to language teaching that places styles and strategy instruction in the center of its learner-based approach. Learning styles are general approaches learners take towards learning, the way they prefer to organize and retain information. For example, learners may be visually oriented and learn better when they are exposed to visual stimuli (visual) or they may be auditory oriented learners who remember information better when they listen to the information they receive (auditory). Some learners prefer to have active participation in the process of learning and learn by experiencing by themselves (kinesthetic) and still some other learners prefer to experience hands-on training in field-trips and laboratory settings to learn information (tactile). Strategies are actions that are taken to learn things. Strategies are often linked to preferred learning styles (Rossi-Le, 1995). For example, an auditory learner may use read aloud strategies when reading a text or a kinesthetic learner may walk around when learning a new set of words.

An SSBI approach to language teaching has two main goals: styles and strategy instruction which includes the explicit instruction of learning styles and strategies so that learners get an understanding of their preferred learning styles, and the integration of styles and strategy which involves embedding learning styles and strategies into all classroom activities so that learners have the opportunity for contextualized practice. This practice provides reinforcement of the concepts learned during explicit instruction.

O'Malley and Chamot (1990) proposed the Cognitive Academic Language Learning Approach (CALLA) which 
combines four primary elements for successful language teaching: (1) academic content for language learning, (2) learning strategies, (3) standards-based education, and (4) portfolio assessment. One assumption of this approach is that L2 acquisition is accelerated by an explicit focus on strategies instruction. They emphasize that the CALLA framework integrates research from several previous studies and puts it into practice. Their extensive research has resulted in the metacognitive model of strategic learning and the framework for learning strategies instruction.

The CALLA (Chamot, 2005; Chamot, et al., 1999) model comprises six stages. They are:

(1) Preparation. In this stage, students' current learning strategies for familiar tasks such as recalling their prior knowledge, previewing the key vocabulary to be introduced to the lesson are identified by the teacher;

(2) Presentation. In this phase, by modeling, naming or explaining the new strategy; the teacher asks students if and how they have used it. Examples for these strategies are selective attention, self-monitoring, inferencing, elaboration, and note-taking strategies;

(3) Practice. In practice stage, the students are given the opportunity to practice new strategy; in later strategy practice, the teacher eliminates the reminders to encourage independent strategy use by asking to check the language they produce, prepare an oral or written report or classify concepts;

(4) Evaluation. In this stage, the students, immediately after practice, evaluate their own strategy use. To this end, they give a summary individually or cooperatively to determine the effectiveness of their own learning;

(5) Expansion activities. In this stage, the strategies are transferred to new tasks by the students. To do this, the students combine strategies into clusters, develop a record of strategies they preferred and integrate them into their existing knowledge frameworks.

(6) Assessment. In the last phase, the teacher evaluates the students' application of strategies and its impact on their performance.

Chamot's model, in essence, integrates strategy learning into the content-based and academic activities. One of the features of the CALLA model is its recursiveness rather than being a linear model. This allows the teachers and students to repeatedly review the prior instructional phases when needed (Chamot, 2005). His model is useful for language learners of different levels and has been considered as a guide for implementing a whole-language or language-across-curriculum approach to instruction.

\section{Strategy-based Research within the Language Skills}

Significant research has been conducted on the use of specific strategies in the four language skills of listening, speaking, reading and writing. A brief account of the research conducted on the use of learning strategies in each language skill follows.

Listening strategies. Listening strategies used by L2 learners have been shown to be influencing their listening comprehension skill (O’Malley \& Chamot, 1990; Goh, 1997;
Cheng, 2002; Chien \& Kao, 2002). Vandergrift (1997,1999, 2002 ) is the researcher specifically engaged in strategy research within the context of L2 listening. 420 children in 17 different Grade 4-6 classes in Canada participated in a project on metacognitive strategy awareness in Vandergrieft's study. In this project, the learners were asked to respond to three listening tasks and a guided reflection activity. After the learners finished the listening tasks, the teachers engaged the classes in reflective exercises to determine how the listeners approached the tasks and what they learned in French. Results indicated that students enjoyed a high level of awareness of their strategies that they had used while engaged in the listening tasks. In particular, the learners clearly applied metacognitive strategies of planning, monitoring, and evaluating during the listening task. Vandergrift emphasizes the importance of teaching language content as well as learning processes through strategies.

Speaking strategies. The most notable research on the use of strategies in speaking activities in classes was the one conducted by Dornyei (1995) and the study by Cohen and Olshtain (1993). In their study, Cohen and Olshtain applied retrospective think-aloud protocols to get L2 learners to report the ways in which they assess, plan, and execute their spoken utterances. They videotaped 15 L2 learners participating in role-play situations with native English. Different speech act situations such as two apologies, two complaints, and two requests (totally six) were provided for each learner. After each set of two speech acts, the video was repeated for the learners, who then responded in their L1 to a set of questions about what they were thinking during the role-plays. Cohen and Olshtain report from the data that learners in their study are classified into three types: metacognizers, avoiders and pragmatists. The results indicate that in using the strategies to perform speech acts, the subjects utilized four primary strategies: (1) planning to use a particular vocabulary and grammatical structure, (2) thinking in two languages, (3) using a variety of different strategies when searching for language forms, and (4) not paying much attention to pronunciation or grammar. This research supports the claims that learners can be aware of their strategies and report them to researchers and teachers. This awareness facilitates language learning.

Reading Strategies. Significant research has been conducted on the metacognitive reading strategies of L2 learners by Sheorey and Mokhtari (2001) and Mokhtari and Sheorey (2002). They developed an instrument called the Survey of Reading Strategies (SORS) to measure the metacognitive reading strategies of $\mathrm{L} 2$ readers involved in reading academic materials. They applied SORS in a study with 152 native-speaking students and 152 ESL students in order to examine the differences in the usage of reading strategy between native and non-native speakers of English. The results indicated that the ESL students showed a higher use of strategies than the native US students. The ESL students also reported using many support strategies. Sheorey and Mokhtari (2001, p.445) state that "skilled readers... are more able to reflect on and monitor their cognitive processes while reading. They are aware not only of which strategies to use, but they also tend to be better at regulating the use of such strategies while reading". 
Anderson (1991, pp. 468-9) highlights that:

Strategic reading is not only a matter of knowing what strategy to use, but also the reader must know how to use a strategy successfully and orchestrate its use with other strategies. It is not sufficient to know about strategies; a reader must also be able to apply them strategically.

Writing Strategies. The strategies used by L2 learners in their writing tasks were also studied by different researchers. He's (2002) research involved 38 Taiwanese college-level writers. They were divided into two groups: mastery-orientation (those with intrinsic motivation to improve their writing skill) and performance-orientation (those with extrinsic motivation to have higher ability in writing than other writers) classes. The goal of this classification was to find out whether the learners' goal orientation would influence their strategy use. The results indicated that the writers in both groups reported using strategies in five categories of planning, monitoring/evaluating, revising, retrieving, and compensating strategies. Writers in the mastery-orientation group reported greater application of strategies in the monitoring/ evaluating, revising and compensating categories. They also wrote better essays than the performance-orientation group. Finally, revising strategies and mastery orientation served as two significant predicators of successful writing.

\section{METHODOLOGY}

\section{Participants}

This study was conducted at Tabriz Islamic Art University in Tabriz, Iran. The participants involved in this experiment were 28 and 26 undergraduate male students who studied Islamic Arts and Architectural Engineering, respectively. The participants were randomly divided into two experimental and two control groups. Based on their scores on the General English section of the university entrance exam, they were considered to have intermediate knowledge of English.

\section{Design of the Study}

The design of this study in true-experimental designs is "randomized subjects, posttest-only control group design”. According to Ary et al. (2010), this design is one of the most powerful of all experimental designs, since it has the two essential elements necessary for maximum control of the threats to internal validity: randomization and a control group. The randomization controls for all possible extraneous variables and makes sure that any initial differences between the groups are attributed only to chance and therefore will follow the laws of probability. The control group controls the effect of the treatment given to the experimental group on the independent variable and shows that any change in it can be attributed to the treatment that the experimental group received.

\section{Procedure}

This study was intended to experiment the effect of strategy instruction on students' ESP reading comprehension ability.
To this end, two groups of the students studying Islamic Art $(n=28)$ and Architecture Engineering $(n=26)$ were randomly chosen as the target population. They enrolled in a mandatory course named General English with three credits as part of their educational curriculum for three hours a week. The participants in each group were randomly assigned as our experimental and control groups in each class. The control groups in Engineering and Art groups, 13 and 14 students respectively, were given the usual lessons in General English course but the experimental groups, 13 and 14 students respectively, were given a treatment along with their usual lessons in the course. The treatment was the explicit instruction of three metacognitive reading strategies during the term. They received this treatment for 45 minutes each session during 15 weeks of the term. The metacognitive strategies chosen to be instructed were "previewing the text before reading, using context clues, and predicting or guessing text meaning". For this purpose, each session, a short technical intermediate passage in their field was given to the participants in the experimental groups and the metacognitive strategies were explained and practiced with them.

The model that was used for strategy instruction was the one developed by Chamot (1999). Chamot's model, in essence, integrates strategy learning into the content-based and academic activities. As mentioned before, one of the essential characteristics of the CALLA model is its recursiveness rather than being a linear model. This provides the possibility for the teachers and students to repeatedly review the prior instructional phases when necessary (Chamot, 2005). His model is useful for language learners of different levels and has been considered as a guide for implementing a whole-language or language-across-curriculum approach to instruction. The CALLA is composed of six steps that are Preparation, Presentation, Practice, Evaluation, Expansion activities, and Assessment.

The control group in each Art and Engineering classes also received some practice on reading technical passages in their fields without any explicit instruction of the reading strategies that experimental groups received. In the control groups, the students were simply asked to read the technical short passages in class and give Persian translations to ensure their full understanding of the texts. Some necessary explanations about the meaning of difficult words, expressions or grammatical points were also presented when there were any questions. At the end of the term, a posttest was administered to the experimental and control groups and the students' mean of the scores on the posttest were analyzed, using the SPSS software. For analyzing the scores, the mean scores in each experimental and control groups were analyzed by independent t-test. The posttest consisted of four reading passages in Architecture and Islamic Arts fields, each of which followed by five reading comprehension questions.

\section{RESULTS}

The following tables show the descriptive and inferential statistics of the participants in each experimental and control group. As table 4.1 indicates, the mean of the scores for the Art control group is 69.28 and the one for the experimental 
group is 76.78 and the means for the Engineering control and experimental groups are 76.15 and 82.69 , respectively. The mean scores show that the experimental groups, who received the treatment, outperformed the control groups. But in order to scientifically claim that the higher mean of the scores in the experimental groups was statistically significant, an independent t-test was run on the scores and the results are presented in Tables 4.2.and 4.3.

\section{Response to the Research Question 1}

The data obtained from the experimentation of the explicit instruction of metacognitive reading strategies showed a better performance of the experimental Art group compared with the control one. The result of independent $t$ - test run on the mean of the scores on the post test of the experimental and control groups among Art students revealed that the difference between the mean of the scores is statistically significant.

As it is clear from Tables 4.2, the t value (2.307) in Art group is greater than 0.05 alpha level of significance for twotail test $(\mathrm{df}=26, \mathrm{t}$ critical $=2.056)$ and $\mathrm{t}$ sig. value is 0.029 and smaller than $0.05(\mathrm{p}<0.05)$. This means that the null hypotheses can be rejected and our research hypothesis is confirmed. In other words, the results of the independent t-test on the mean scores of the control and experimental Art

Table 4.1. Descriptive statistics of posttest scores of control and experimental groups among art and engineering students

\begin{tabular}{llcccc}
\hline & group & N & Mean & $\begin{array}{c}\text { Std. } \\
\text { deviation }\end{array}$ & $\begin{array}{c}\text { Std. } \\
\text { error } \\
\text { mean }\end{array}$ \\
\hline Art & $\begin{array}{l}\text { control group } \\
\text { experimental }\end{array}$ & 14 & 69.2857 & 9.37614 & 2.50588 \\
Eng. & group & & & & \\
control group & 13 & 76.1538 & 8.69718 & 2.41217 \\
& $\begin{array}{l}\text { experimental } \\
\text { group }\end{array}$ & 13 & 82.6923 & 4.38529 & 1.21626 \\
\hline
\end{tabular}

groups statistically prove that the treatment the experimental group received was beneficial to them and that there is a positive effect of explicit instruction of metacognitive reading strategies on Art students' ESP reading comprehension ability. So, it is statistically shown that the experimental groups benefited from the explicit strategy instruction.

\section{Response to Research Question 2}

With respect to the second group of participants in the experimentation of the effect of explicit instruction of metacognitive reading strategies on Science students' ESP reading comprehension ability, the results obtained from the analysis of independent $t$ - test on the mean of the scores the experimental and control groups obtained on the post test indicate that the experimental group outperformed the control one and showed better achievements with regard to their reading comprehension ability in ESP materials. In other words, it was revealed that the difference between the mean of the scores of the experimental and control groups among engineering students was statistically significant.

As Tables 4.3 indicates, the t value (2.420) is greater than 0.05 alpha level of significance for two-tail test $(\mathrm{df}=24, \mathrm{t}$ critical $=2.064$ ) and $t$ sig. value is 0.023 and smaller than $0.05(p<0.05)$ for Engineering groups. This means that the null hypothesis can be automatically rejected and our research hypothesis is confirmed. In other words, the results of the independent t-test on the mean of the scores of the control and experimental Engineering groups statistically prove that the experimental group was benefited from the treatment they received and that there is a positive effect of explicit instruction of metacognitive reading strategies on Engineering students' ESP reading comprehension ability.

\section{DISCUSSION}

In this study it was found that explicit instruction of metacognitive reading strategies has a positive effect on the learners' reading comprehension ability in ESP texts. The findings of this study are in line with the findings that were reported

Table 4.2. The result of independent T-test on art students' posttest scores in control and experimental groups

\begin{tabular}{|c|c|c|c|c|c|c|c|c|c|}
\hline & \multicolumn{2}{|c|}{$\begin{array}{l}\text { Levene's test } \\
\text { for equality of } \\
\text { variances }\end{array}$} & \multicolumn{3}{|c|}{ T-test for equality of means } & \multirow{3}{*}{$\begin{array}{c}\text { Mean } \\
\text { difference }\end{array}$} & \multirow{3}{*}{$\begin{array}{l}\text { Standard } \\
\text { error } \\
\text { difference }\end{array}$} & \multirow{2}{*}{\multicolumn{2}{|c|}{$\begin{array}{l}95 \% \text { confidence interval } \\
\text { of the difference }\end{array}$}} \\
\hline & \multirow[t]{2}{*}{$\mathbf{F}$} & \multirow[t]{2}{*}{ Sig. } & \multirow[t]{2}{*}{ Difference } & \multirow[t]{2}{*}{ df } & \multirow[t]{2}{*}{ Sig. (2-tailed) } & & & & \\
\hline & & & & & & & & Lower & Upper \\
\hline \multicolumn{10}{|l|}{ Art } \\
\hline $\begin{array}{l}\text { Equal variances } \\
\text { assumed }\end{array}$ & 1.019 & 0.322 & -2.307 & 26 & 0.029 & -7.500 & 3.25071 & -14.18193 & -0.81807 \\
\hline $\begin{array}{l}\text { Equal } \\
\text { variances not } \\
\text { assumed }\end{array}$ & & & -2.307 & 25.108 & 0.030 & -7.500 & 3.25071 & -14.19350 & -0.80650 \\
\hline
\end{tabular}


Table 4.3. The result of independent t-test on engineering students' posttest scores in control and experimental groups

\begin{tabular}{|c|c|c|c|c|c|c|c|c|c|}
\hline & \multicolumn{2}{|c|}{$\begin{array}{l}\text { Levene's test } \\
\text { for equality of } \\
\text { variances }\end{array}$} & \multicolumn{3}{|c|}{ T-test for equality of means } & \multirow{3}{*}{$\begin{array}{c}\text { Mean } \\
\text { difference }\end{array}$} & \multirow{3}{*}{$\begin{array}{l}\text { Standard. } \\
\text { error } \\
\text { difference }\end{array}$} & \multirow{2}{*}{\multicolumn{2}{|c|}{$\begin{array}{l}95 \% \text { confidence interval } \\
\text { of the difference }\end{array}$}} \\
\hline & \multirow[t]{2}{*}{$\mathbf{F}$} & \multirow[t]{2}{*}{ Sig. } & \multirow[t]{2}{*}{ Difference } & \multirow[t]{2}{*}{ df } & \multirow[t]{2}{*}{ Sig. (2-tailed) } & & & & \\
\hline & & & & & & & & Lower & Upper \\
\hline \multicolumn{10}{|l|}{ Eng. } \\
\hline $\begin{array}{l}\text { Equal } \\
\text { variances } \\
\text { assumed }\end{array}$ & 4.244 & 0.050 & -2.420 & 24 & 0.023 & -6.53846 & 2.70145 & -12.11398 & -0.96294 \\
\hline $\begin{array}{l}\text { Equal } \\
\text { variance s } \\
\text { not assumed }\end{array}$ & & & -2.420 & 17.731 & 0.026 & -6.53846 & 2.70145 & -12.22017 & -0.85675 \\
\hline
\end{tabular}

by other similar empirical studies. For instance, focusing on the influence of strategy instruction and the students' reading comprehension of ESP texts, Moghadam (2008), used Janzen's (2002) procedure to teach cognitive reading strategies to Fisheries students at Mirza Koochak Khan Higher Fisheries Education Center and see its effect on the students' ESP reading comprehension. The results showed that the experimental group who received treatment in the form of cognitive strategy instruction during 13 weeks of practice performed better than the control group who did not receive the instruction.

In another investigation, Takallou (2011) studied the effect of metacognitive strategy instruction on EFL learners' reading comprehension performance and metacognitive awareness with 93 male and female EFL students and found that the experimental groups who received instruction on metacognitive strategies (planning and self-monitoring) outperformed the control group on the reading comprehension test. She also reported that text type played an important role in the subjects' reading comprehension. In her study, the subjects performed better on authentic texts. In addition, the results showed that, after the instruction was provided for the experimental group, their awareness to metacognitive strategies significantly increased. Similar results have been reported by other studies.

In an article about learning styles as predicators of students' test performance, Ajideh and Gholami (2014) investigated 152 undergraduate EFL students' learning style preferences and its role on their test performance. They administered a questionnaire to identify the students' preferred learning styles. At the end of the usual term, their scores on final exam were analyzed using multiple regression analysis. The results revealed that out of four learning styles of theorists, activists, reflective and pragmatist as possible predicators, only reflective and pragmatist styles accounted for a statistically significant portion of the variance in final exam performance.

In their study on the influence of explicit metacognitive strategy instruction on reading comprehension and self-efficacy beliefs on Iranian university EFL students, Tavakoli and Koosha (2016) collected data by the Survey of Reading Strategies (SORS), Motivated Strategies for Learning Questionnaires (MSLQ) and a reading comprehension test. The results of ANCOVA analyses indicated that the students in the experimental group who received instruction on metacognitive reading strategies showed greater achievement both in reading comprehension and self-efficacy than those students in the control group.

In another study, Khaokaew (2012) investigated the effect of explicit strategy instruction on EFL reading of undergraduate English majors in Thailand. As her PhD dissertation, she conducted a quasi-experimental research in which the experimental group was given a course in reading that lasted for twelve weeks and included explicit strategy instruction in reading strategies. On the other hand, a parallel course that did not include any overt strategy instruction was given to the control group. At the end of the course, the participants in both groups took reading tests and responded to questionnaires about their use of strategies at the beginning and end of their courses. The participants were also asked to perform think-aloud verbal protocols in which they reported in their use of reading strategies when they were engaged in reading tasks. She finally reported that experimental group used a wider range of strategies than those in the control group following the instruction they received. They also made greater improvements in their reading test scores.

The empirical studies mentioned above along with the findings of this study all indicate that explicit instruction of metacognitive reading strategies has a positive effect on the students' final performance. Though some researchers have expressed skepticism about the effectiveness of explicit strategy instruction (e.g. Rees-Miller,1993; 1994) and recommend teachers to be cautious to accept the concept of learner strategy training, as Chamot and Rubin (1994) point out, no single strategy is used in isolation, but rather in an orchestrated manner with other strategies as part of a process. This should not suggest that strategy instruction is not effective, but rather give teachers increased insight into the various factors they take into consideration when strategy instruction is undertaken.

\section{IMPLICATIONS}

The findings of this study can have several implications for learners, teachers and material developers. The first impli- 
cation is for the learners themselves. They need to be aware of their reading strategies on the one hand and building appropriate reading strategies on the other to help them approach tackling their reading activities in general and reading their technical materials in their field in particular more skillfully, and achieve their reading objectives more autonomously. In this way, they have the chance to get responsibility over their own learning and enhance their self-autonomy and independence (Dickinson, 1987). According to Oxford and Crookall (1989), learners need to acquire these abilities since they need to keep on reading even if they do not find the opportunity to enroll in formal classes, and to this end, having responsibility for their own learning and building appropriate self-autonomy and independence play a major role.

Teachers also need to find different ways of identifying learners' preferred reading strategies by using different data collection techniques such as using self-report questionnaires, interviews and verbal reports. In this way, they can increase the learners' metacognitive awareness of their reading strategies and let them know how to use them more effectively for different reading purposes. Teachers also need to explicitly teach learners different applications of reading strategies in detail and help them realize how beneficial it can be for them to know the right strategies and when and where to apply them. To this end, various conscious raising techniques need to be used in the classroom through the application of reading tasks in their technical fields. The learners also need to be taught how to self-evaluate the reading strategies they apply and monitor their development more efficiently. The constructive feedback itself that the teachers provide for the students in this respect can play an essential role to help them be aware of their weaknesses and strengths regarding reading strategy use and to expand their strategic knowledge beyond their ESP classes.

Material developers could play an important role by designing and incorporating appropriate tasks and exercises into the reading materials in order to encourage a wide range of strategy application in the learning experiences and finally enhance learner independence and autonomy. They need to bear in mind the individual differences among learners and design tasks with a variety of forms so that it can be ensured that learners with different individualistic characteristics are accounted for.

\section{CONCLUSION}

There has been great emphasis on the importance of explicit instruction of strategy use in language classes and the positive effect of this instruction on learners' achievements. This study tried to investigate the effect of explicit strategy instruction on metacognitive reading strategies of Art and Engineering students' ESP reading comprehension skill. The results of independent $t$ - test indicated that the experimental groups in this study who received explicit instruction on metacognitive reading strategies showed a better performance on ESP reading test than the control groups who did not receive this instruction. The findings of this study also showed that explicit instruction of metacog- nitive reading strategies can positively enhance learners' ESP reading comprehension ability. Therefore, as Nunan (1996) points out, there needs to be a dual focus in language classrooms to teach not only language content but also to develop learning processes as well. To this end, the primary purpose of strategy instruction is to raise learners' awareness of strategies and then allow each to select appropriate strategies to accomplish their learning goals. In conclusion, it can be suggested that in ESP reading classes, as well as EFL classes, the focus should be not only on teaching language content but also on developing efficient learning processes through strategy instruction and awareness-raising (Ellis \& Sinclair, 1989; Willing, 1990; Nunan, 1995a, 1995b).

\section{ACKNOWLEDGEMENTS}

We would like to express our sincere thanks to the respected anonymous reviewers for their useful suggestions and comments on the earlier versions of this paper.

\section{REFERENCES}

Ajideh, P., Gholami, V. (2014).Learning styles as predicators of students' test performance. English Language Teaching,(1)3, 1-17.

Anderson, N. J. (1991). Individual differences in strategy use in second language reading and testing. Modern Language Journal, 75(4), 461-472.

Anderson, N. J., (2002). The role of metacognition in second/foreign language teaching and learning. ERIC Digest. Washington DC.

Anderson, N. J., (2005). L2 Learning Strategies. In E. Hinkel (Ed.), Handbook of Research in Second Language Teaching and Learning. (pp. 757-771). Lawrence Erlbaum Associates, Inc. New Jersey.

Anderson, N. J., \&Vandergrif, L. (1996). Increasing Metacognitive Awareness in the L2 Classroom by Using Think-aloud Protocols and Other Verbal Report Formats. In R. L. Oxford (Ed.), Language Learning Strategies Around the World: Crosscultural Prespectives (pp. 3-18). National Foreign Language Resource Center. Manoa: University of Hawaii Press.

Ary, D., Jacobs, L. C., Razavieh, A., \& Sorenson, C. K. (2006).Introduction to research in education. Belmont, CA: Thomson Higher Education.

Brown, H. D. (2002). Strategies for success: A practical guide to learning English. New York, Longman.

Chamot, A. U. (2005). The Cognitive Academic Language Learning Approach (CALLA):An update. In P. A. Richard-Amato \& M. A. Snow (Eds.), Academic success for English language learners: Strategies for K-12 mainstream teachers(pp. 87-101). White Plains, NY: Longman.

Chamot, A. U., Barnhardt, S., El-Dinary, P. B., \& Robbins, J. (1999).The learning strategies handbook. New York: Longman.

Chamot, A. U., \& O'Malley, M. (1994). The CALLA handbook: Implementing the cognitive academic language 
learning approach. White Plains, NY: Addison Wesley Longman.

Chamot, A. U., \& Rubin, J. (1994). Comments on Janie Rees-Miller's 'A critical appraisal of learner training theoretical bases and teaching implications.' TESOL Quarterly, 28(4),771-781.

Cheng, C. H., (2002).Effects of listening strategy instruction on junior highschool students. In J. E. Katchen (Ed.), Selected papers from the Eleventh International Symposium on English Teaching/Fourth Pan Asian Conference. (289-297). Taipei, Taiwan.

Chien, C. N., \& Kao, L. H., (2002). Effects of metacognitive strategy on listening comprehension with EFL learners. In J. E. Katchen (Ed.), Selected papers from the Eleventh International Symposium on English Teaching/Fourth Pan Asian Conference. (pp. 298-307) Taipei, Taiwan.

Cohen, A. D., (1996a). Second Language Learning and Use Strategies: Clarifying the Issues. CARLA Working Paper Series \#3. Minneapolis, MN: The University of Minnesota.

Cohen, A. D., (1998). Strategies in learning and using a second language. New York: Longman.

Cohen, A. D., \& Olshtain, E. (1993) The production of speech acts by EFL learners. TESOL Quarterly, 27(1), 33-56.

Cohen, A. D., \& Scott, K. (1996). A synthesis of approaches to assessing language learning strategies. In R. L. Oxford (Ed.), Language learning strategies around the world: Crosscultural perspectives (pp. 89-106). Manoa: University of Hawaii Press.

Cohen, A. D., Weaver, S. J., \& Li, T.-Y. (1998). The impact of strategies-based instruction on speaking a foreign language. In A. D. Cohen (Ed.), Strategies in learning and using a second language (pp. 107-156). London: Longman.

Dickinson, L. (1987). Self-instruction in language learning. Cambridge: Cambridge University Press.

Dörnyei, Z. (1995). On the teachability of communication strategies. TESOL Quarterly,29(1), 55-85.

Ellis, G., \& Sinclair, B. (eds.). (1989). Learning to learn English learner's book: A course in learner training (Vol. 1). Cambridge University Press.

Gass, S. \& Mackey, A. (2000). Stimulated recall methodology in second language research. Mahwah, NJ: Lawrence Erlbaum Associates.

Goh, C., (1997).Metacognitive awareness and second language listeners.ELT Journal, 51, 361-369.

Graham, S., \& Harris, K. (2000).The role of self-regulation and transcription skills in writing and writing development. Educational Psychologist, 35(1), 3-12.

He, T. H., (2002). Goal orientations, writing strategies, and written outcomes: An experimental study. In J. E. Katchen (Ed.), Selected papers from the Eleventh International Symposium on English Teaching/Fourth Pan Asian Conference.(pp. 198-207), Taipei, Taiwan.

Hsiao, T. Y., \& Oxford, R. L. (2002). Comparing theories of language learning strategies: A confirmatory factor analysis. Modern Language Journal, 86(3), 368-383.
Khaokaew, B. (2012). An Investigation of Explicit Strategy Instruction on EFL Reading of Undergraduate English Majors in Thailand.Unpublished PhD dissertation. University of Bedfordshire

Moghadam, M. Kh. (2008). The effect of strategies-based instruction on student's reading comprehension of ESP texts. MirzaKoochak Khan Higher Fisheries Education Centre. Rasht, Iran.

Mokhtari, K., \& Shoerey, R. (2002). Measuring ESL students' awareness of reading strategies. Journal of Developmental Education, 25(3), 2-10.

Naiman, N., Fröhlich, M., \&Todesco, A. (1975).The good language learner. Toronto: Ontario Institute for Studies in Education.

Nunan, D. (1991). Language Teaching Methodology: A Textbook for Teachers. New York: Prentice-Hall.

Nunan, D. (1995a). Closing the gap between learning and instruction. TESOL Quarterly, 29(1), 133-158.

Nunan, D. (1995b). Atlas: Learning-centered communication. Levels 1-4. Boston, MA: Heinle \& Heinle Pub.

Nunan, D. (1996). Learner strategy training in the classroom: An action research study. TESOL Journal, 6(1), 35-41.

Nunan, D. (1997). Does learner strategy training make a difference? Language Modernas, 24, 123-142.

O’Malley, J. M., \& Chamot, A. U. (1990). Learning strategies in second language acquisition. Cambridge: Cambridge University Press.

Oxford, R. L. (1990). Language learning strategies and beyond: A look at strategies in the context of styles. In S. S. Megan (Ed.),Shifting the instructional focus to the learner. (pp. 35-55). Middlebury, VT: Northeast Conference on the Teaching of Foreign Language.

Oxford, R. L. (2001). Language learning strategies. In R. Carter \& D. Nunan (Eds.), The Cambridge guide to teaching English to speakers of other languages. (pp. 166-172).Cambridge: Cambridge University Press.

Oxford, R. L. (1993). Style Analysis Survey (SAS). Tuscaloosa, AL: University of Alabama.

Oxford, R. L., \& Burry-Stock, J. A. (1995). Assessing the use of language learning strategies worldwide with the ESL/EFL version with the strategy inventory of language learning (SILL). System, 23(1), 1-23.

Oxford, R. L., Lavine, R. L., Felkins, G., Hollaway, M. E., Saleh, S. (1996). Telling their stories: Language students use diaries and recollection. In R. L. Oxford (Ed.), Language learning strategies around the world: Crosscultural perspectives (pp. 89-106). Manoa: University of Hawaii Press.

Oxford, R. L., \& Leaver, B. L., (1996). A synthesis of strategy instruction for language learners. In R. L. Oxford (Ed.), Language learning strategies around the world: Crosscultural perspectives (pp. 227-246). National Foreign Language Resource Center. Manoa: University of Hawaii Press.

Oxford, R., L., \&Crookall, D. (1989). Research on language learning strategies: Methods, findings, and instructional issues. The Modern Language Journal, 73(4), 404-419.

Rees-Miller, J., (1993). A critical appraisal of learner training: Theoretical bases and teaching implications. TESOL Quarterly, 27, 679-689. 
Rees-Miller, J., (1994). The author responds. TESOL Quarterly, 28, 776-781.

Riley, L. D., \& Harsch, K., (1999). Enhancing the learning experience with strategy journal: Supporting the diverse learning styles of ESL/EFL students. Proceedings of the HERDSA Annual International Conference, Melbourne, Australia. Retrieved on October 25, 2016 from http:// hersda.org.au/vic/cinferences/pdf/Rikley.PDF

Rossi-Le, L. (1995).Learning styles and strategies in adult immigrant ESL students. In J. M. Reid (Ed.), Learning styles in the ESL/EFL classroom(pp. 118-125). Boston: Heinle \& Heinle.

Rubin, J. (1981). Study of cognitive processes in language learning.Applied Linguistics. 2(2), 117-131.

Sheorey, R., \& Mokhtari, K. (2001). Differences in the metacognitive awareness of reading strategies among native and non-native readers. System, 29(4), 431-449.

Takallou, F. (2011). The effect of metacognitive strategy instruction on EFL learners' reading comprehension performance and metacognitive awareness. Asian EFL Journal, 12, 272-300.

Tavakoli, H., Koosha, M., (2016).The effect of explicit metacognitive strategy instruction on reading comprehension and self-efficacy beliefs: The case of Iranian university EFL students. PortaLinguarum, 25, 119-133.

Vandergrift, L., (1997). The strategies of second language (French) listeners: A descriptive study. Foreign Language Annals, 30, 387-409.

Vandergrift, L., (1999). Facilitating second language listening comprehension: Acquiring successful strategies. ELT Journal, 53, 168-176.

Vandergrift, L., (2002). It was nice to see that our predictions were right: Developing metacognition in L2 listening comprehension. The Canadian Modern Language Review, 58, 555-575.

Willing, K. (1990).Teaching how to learn. Sydney, Australia. National Center for English Language Teaching and Research. 